\title{
O DIREITO ANTROPOLÓGICO
}

\author{
Pablo de Camargo Cerdeira \\ Aluno do Curso de Graduação da Faculdade de Direito da \\ Universidade de São Paulo
}

Resumo:

Este texto versa sobre o Direito antropológico, uma das teorias do Direito pertencente à chamada corrente do culturalismo jurídico. Foca-se, entretanto, nas diferenças entre elas, algumas fundamentais como, por exemplo, na determinação do objeto da ciência jurídica.

Abstract:

This text is about the anthropological law, one of the theories of the law belonging to the called law culturalism. It is focused, however, in the differences among them, some of then fundamentals, as, for instance, in the determination of the object of the law science.

Unitermos: Antropologia; Direito pressuposto; Filosofia do Direito; teorias do Direito. da história do Direito?'

* que é Direito? Em que se funda ou se legitima o Direito? Qual o sentido

A flexão sobre tais questões, comumente subvalorizadas por boa parte dos acadêmicos de Direito, é vital para que se teça um correto raciocínio acerca de muitos dos maiores problemas jurídicos enfrentados pelos profissionais da área, qualquer que seja sua especialização. É a partir das respostas às questões anteriores, que variarão de acordo com a teoria adotada, que se saberá responder com maior propriedade questões que versem sobre, por exemplo, os conflitos de leis no espaço, tão em voga nos tempos de globalização; ou, ainda, os problemas enfrentados quando dos estudos sobre a fonte de que emana a força de qualquer dos princípios administrativos, como o princípio da legalidade ou da publicidade. As aplicações das teorias do Direito, dos aspectos filosóficos sobre este, não apenas cabem em praticamente todas as questões jurídicas, mas, além, são também basilares na estruturação das buscas por respostas.

* N. R.: "A composição do texto como ele aqui se apresenta, iniciando-se no meio de uma frase, sem conclusāo e terminando com a introdução, sem ") término da frase final, näo constitui erro de edição. $\hat{E}$. sim, estilo adotado pelo autor."

I. Liçĩes Preliminares de Direito, São Paulo, 24 ed., Saraiva, 1998. 


\section{O Direito antropológico.}

Neste texto trataremos da fundamentação cultural do Direito, teoria que chamaremos de Direito antropológico ou Direito pressuposto - esta última denominação originada diretamente dos ensinamentos do professor Eros Roberto Grau ${ }^{2}$. Aqui, Direito antropológico será tratado como sinônimo de Direito pressuposto. Adotaremos um nome diferente do escolhido pelo professor Eros Grau com a finalidade de tornar mais clara a ligação existente entre a cultura e o direito, sem qualquer crítica ao termo por ele adotado.

É, entretanto, fundamental que se note desde já que existem diversas teorias denominadas do "Direito cultural", e que a Teoria do Direito pressuposto não se confunde com as demais por uma série de razões, expostas todas no momento devido. Assim, quando falarmos sobre o Direito cultural - em sentido estrito, note-se, no singular - não estamos falando de Direito antropológico, mas, se falarmos de "direitos culturais" aí estaremos abrangendo tanto as teorias do Direito cultural como a Teoria do Direito pressuposto ou antropológico.

O Direito antropológico e o Direito cultural ainda em sentido estrito são espécies do gênero direitos culturais -, aqui em sentido largo.

Também é base para este estudo os ensinamentos de Friederich von Savigny. O jurista alemão, responsável pela fundação da Escola Histórica do Direito, foi ferrenho defensor da origem cultural deste. Sua posição, entretanto, carregava forte base política vez que, naquela época, a Alemanha passava por um momento peculiar, com parte dos juristas apoiando a adoção do Código de Napoleão na íntegra, o que iria contra uma série de costumes enraizados nos estados que compunham a nova Confederação pós Congresso de Viena.

Antes de entrarmos no aspecto eminentemente jurídico, onde veremos as diferenças entre os tipos de direitos culturais, é de fundamental importância que se explique o que se entende por Antropologia e, conseqüentemente, por Direito antropológico.

\section{O estudo antropológico.}

O estudo antropológico tem como objeto o "instrumental superorgânico do homem" " ou seja, sua cultura. É dentro desse instrumental que, segundo nossa posição, se encontra o Direito, tal qual a linguagem, a física, a economia, a música e todos os demais conhecimentos não instintivos do ser humano.

Desde há tempos, os estudiosos das ciências sociais buscam entender onde, como e quando ocorreu a diferenciação entre o Homo Sapiens e os demais animais. Tais estudos iniciaram-se já com Platão, com a definição de homem como um animal

\section{Direito Posto e Direito Pressuposto, São Paulo, Malheiros, 1996.}

3. A. KROEBER, $O$ superorgânico in Donald Pierson, Estudos de organização social, São Paulo, Livraria Martins, 1949. 
racional, ou com Aristóteles, que o define como um animal político. Mas apenas por volta do final do século XVII, quando do Ensaio acerca do entendimento humano, de John Locke, realizado em 1690 e, posteriormente, com o trabalho de Jean-Jacques Rousseau, intitulado Discurso sobre a origem e o estabelecimento da desigualdade entre os homens, de 1775, é que se iniciam os estudos científicos sobre o que posteriormente seria chamado de cultura ${ }^{4}$. Aquele primeiro trabalho coloca o homem como uma caixa vazia por ocasião do nascimento, dotada apenas de capacidade ilimitada de obter conhecimento. Para Locke, nem mesmo a moral é inerente ao ser humano, tudo é fruto de seu aprendizado e construção. No mesmo sentido Rousseau, quando fixa no seu trabalho que a transição entre o homem e os pongídeos ${ }^{5}$ se deu quando aquele passou a utilizar-se da educação, do ensino. Tal dedução partiu da observação de que muitos dos pongídeos têm capacidade de aprendizado similar à de uma criança humana, o que já bastaria para que eles tivessem, teoricamente, capacidade de evolução para algo parecido com o ser humano. Entretanto, diferentemente dos homens, que ensinam seus filhos, os macacos, mesmo os mais evoluídos, começam seu aprendizado praticamente "do zero", ou seja, a eles não é oferecida a possibilidade de aprender sem experimentar, como o que os homens adultos proporcionam às suas crianças; todos os filhotes dos chimpanzés, por exemplo, só atingem um grau de conhecimento similar ao dos adultos de sua espécie quando também na fase adulta, apenas após ter vivido as experiências necessárias para a construção daquele instrumental. Já com os homens essa evolução é diferente. Eé nesse ponto que Rousseau se apóia: justamente por ter capacidade de ensinar é que o homem se diferenciou dos demais; a cada geração o ser humano tem à disposição, a um custo-trabalho baixíssimo, uma série de informações que foram extremante custosas aos seus antepassados.

Mas a determinação do objeto da antropologia tem seu marco inicial com Edward Tylor, em finais do século XIX, no seu Primitive Culture ${ }^{6}$ Foi ele quem criou o termo cultura (culture), formulado a partir do alemão Kultur-que originalmente versava sobre os aspectos imateriais, espirituais do conhecimento humano - e do Civilization francês - que tem como acepção as realizações materiais do homem. Cultura é, portanto, segundo Tylor, todo o rol de conhecimentos que o homem carrega, seja material ou imaterial, seja físico ou espiritual; é, enfim, tudo o que o homem tem de diferente para com os demais animais. Cultura para ele é, em última instância, a educação, a história, a economia, a língua, a música, a religião, as máquinas, as invenções, e tudo o mais que se avizinha do exposto e que os animais não têm, por mais distintas que possam parecer.

4. R. de B. LARAIA, Cultura - Um conceito antropológico, 14ª ed., Rio de Janeiro, 2001.

5. Dicionário Aurélio (resumido): "Pongídeos (S. m. pl. Zool.) Familia que abrange os grandes macacos, e que compreende o gorila e o chimpanzé da África, e o orangotango e os gibōes da Ásia. Todos os membros desta família são capazes de postura semipedal, têm polegar e primeiro pododátilo que tendem a ser oponentes, polegar reduzido, são destituidos de cauda, e são cattarrinos."

6. E. TYLOR, Primitive Culture, Londres, John Mursay \& Co., 1958. 
A origem do termo "cultura", entretanto, é controversa. Alguns advogam a favor de uma origem latina, não sendo, portanto, uma criação de Tylor. É bem verdade que Cícero já a utilizava em seus textos como, por exemplo, quando se referia ao trato da terra para cultivo como sendo a cultura agri ${ }^{7}$ O fato é que, mesmo o termo não sendo uma criação recente, foi apenas com Tylor que ele passou a ser tomado cientificamente. Ou seja, mesmo que existisse um termo cultura anterior, proveniente do latim, não era o mesmo termo "cultura" que se utilizava para determinar o objeto da ciência chamada Antropologia. Adotaremos neste trabalho, portanto, o conceito de "cultura como todo o instrumental do homem que não é fruto de seus instintos", como os arrolados acima.

Voltemos, pois, a Tylor: este, influenciado pelo darwinismo, classificava o homem de acordo com sua evolução cultural em uma única linha, toda reta, ou seja, baseava-se no unilinearismo. As populações européias representavam um dos extremos, a civilização; já os que não tinha essa cultura estavam abaixo dos europeus e acabaram por receber de Tylor o título de bárbaros; por fim, na outra ponta, os povos de nível cultural "mais baixo" eram tidos como selvagens. Aí ele colocava os índios. Esse tipo de pensamento, entretanto, se tornou a base de muitos dos diversos etnocentrismos pós-Tylor, muitas vezes radical, como o nazismo, sendo, por isso, muito atacado. Para ele, todos os homens tinham apenas uma mesma cultura, suas dilerenças eram resultado do seu grau de evolução.

Franz Boas ${ }^{\mathrm{x}}$, quase no início do século XX, e, de forma mais aprofundada, Stocking", já após a metade do século XX, atacaram a teoria de Tylor com muilo vigor. Eles pregaram, em substituição ao unilinearismo cultural, o multilinearismo, ou seja, a não-hierarquização das diferentes culturas existentes e aceitação das diferenças criadas pelos povos como resultado de sua evolução cultural, o que foi muito bem aceito à época e que se consolidou, prevalecendo como uma "verdade científica" da Antropologia até os dias atuais. Mas como a grande maioria das verdades científicas, principalmente das ciências sociais, não é considerada absoluta e ainda enfrenta alguma resistência. Mas por ser a mais aceita teoria, é essa que seguiremos no presente estudo.

Ainda acerca da superioridade cultural de determinado grupo sobre os demais, é interessante expor o comentário crítico de Montaigne sobre os hábitos antropofágicos dos Tupinambás: Na verdade, cada qual considera bárbaro o que não se pratica em sua terra. Estimo que é mais bárbaro comer um homem vivo do que morto. E é pior esquartejar um homem entre suplícios e tormentos e o queimar aos poucos, ou entregá-lo a cães e porcos, a pretexto de devoção e fé, como vimos ocorrer com conterrâneos. Tudo isso é interessante, mas, que diabos, essa gente não usa calças!

Cabe aqui uma nota curiosa, dentro de parênteses: a mesma citação, frase por frase, letra por letra, é também associada à figura de Maurício de Nassau,

7. M. REALE, Lições Preliminares ..., vide nota I.

8. F. BOAS. The limitation of comparative method of Amthropology', Science, S.N., v. 4, 1896.

9. G. W. STOCKING Jr., Race, Cullure and Evolution, Nova York, Free Press, 1968. 
quando governante do Recife. É mais provável que este último tenha proferido tal comentário quando no Nordeste brasileiro, já que chegou a conviver com índios que praticavam a antropofagia. Por outro lado, aqueles que defendem a autoria de Montaigne nos mostram até mesmo o local onde teriam sido ditas tais palavras: na cidade de Ruão, na França, para onde alguns índios Tupinambás foram levados como curiosidades de um mundo distante e não-civilizado.

Outra questão que foi e ainda é fonte de controvérsias na Antropologia é a que tange à ordem de aparecimento e evolução da cultura e do homem como ser cultural: primeiro o homem esteve preparado para a cultura e então é que passou a desenvolvê-la ou o inverso é que correspondeu à verdade? Geertz ${ }^{10}$ responde a esse questionamento com os estudos realizados sobre fósseis do Australopiteco Africano: este tinha o cérebro com cerca de dois terços do volume do cérebro humano, mas já tinha alguma cultura elementar, inclusive com algumas regras de comportamento em seu grupo. Segundo Clifford Geertz, portanto, não existiu uma ordem de desenvolvimento linear, mas sim uma simultaneidade. E foi apenas graças a essa evolução conjunta que o homem se desenvolveu: o aumento do córtex permitiu o desenvolvimento de tarefas mais elaboradas, e as mesmas tarefas estimularam o desenvolvimento do córtex. Logo, a cultura é fruto do homem, mas o homem é também fruto da cultura. Existe uma relação de simbiose entre a evolução biológica do ser humano e seu desenvolvimento cultural, sem qualquer ordem de precedência ou hierarquização.

Tomados os casos mais específicos, para tornar mais claro, temos que: a música é fruto do homem, mas este só se tornou apto a desenvolvê-la de forma mais elaborada quando evoluiu musicalmente, o que ocorreu quando passou a organizar os sons de forma que se tornassem agradáveis, mesmo que rusticamente. O mesmo se deu com a economia: o homem passou a desenvolver teorias e técnicas econômicas mais complexas na mesma medida em que aplicava as teorias e técnicas mais simples, que estimulavam a criação das mais evoluídas.

Da mesma sorte o Direito. Conforme o homem se organizava socialmente também criava normas de conduta. Tais normas possibilitaram as organizações sociais mais complexas, que, por sua vez, possibilitaram o amadurecimento do Direito.

É essa a base do gênero das teorias culturais do Direito. É desse Direito cultural que falam Emil Lask e Gustav Radbruch, da Escola de Baden, este último autor do Projeto Radbruch, quando ministro da Justiça na Alemanha, que previa a reforma do sistema de política criminal - e Miguel Reale, com sua Teoria da Tridimensionalidade do Direito.

Entretanto, não é esse Direito cultural o mesmo que se pretende na Teoria do Direito antropológico. Existe uma diferença fundamental que reside justamente no fato de se colocar a existência de não um, mas diversos direitos culturais, como será explicado de forma comparativa às demais teorias.

10. C. GEERTZ. A transpossif̧āo para a humanidade, in Panorama da antropologia, Rio de Janeiro, Fundo de Cultura, 1966. 
IV. Dialética ascendente.

O Direito tradicionalmente é dividido em positivo e natural, sendo o primeiro aquele que aparece nas normas jurídicas postas pelo Estado e o outro o Direito "inato" ao ser humano, que pertence à sua natureza, conforme veremos.

Ainda existem diversas outras correntes, como as não menos importantes Racionalistas ou Contratualistas - tidos como subdivisões do Direito Natural -, tendo como representantes, por exemplo, Grócio, Hobbes e Locke; ou ainda as correntes Teológicas, representada, para ilustração, por São Tomás de Aquino. Tais vertentes, entretanto, trabalham sempre com o dualismo entre o direito positivado, colocado ou pelo Estado ou por um Príncipe, por exemplo, e o não-positivado, aquele que pode ter origem na natureza humana, ou em Deus, ou, ainda, em outras fontes. Tais não serão estudados aqui, bastando para este texto, introdutório, a diferenciação, ainda que não a melhor e nem a única, pelo menos mais simples, entre Direito Positivo e Direito Natural.

IV.a.

Por Direito Natural entende-se aquele que independe de ordenamento ou positivação, podendo ter sua origem na natureza ou essência do homem, para os gregos - que não - obstante também a vinculavam aos Deuses -, teológica para os jusfilósofos do medievo ou, ainda contratual, para os modernos. Segundo seus defensores, é um direito não-escrito, não-criado pelo Estado e nem pelos seus titulares, simplesmente existe conjuntamente à natureza do ser humano. Assim o direito à vida, à liberdade.

Comumente associado a um dote divino, desde a Grécia Antiga é aceito como obra dos deuses. Na peça Antígone, de Sófocles, datada de aproximadamente 450 a.C., existe uma passagem muito interessante: uma das maiores punições aos traidores dos soberanos era a proibição do sepultamento de seu cadáver. O corpo do traidor deveria ser deixado insepulto para ser devorado pelos animais. Antígone, proibida por Creonte de sepultar seu irmão Polinices o faz mesmo assim, de forma simbólica, lançando um pouco de terra sobre seu corpo. Repreendida por Creonte, ela alega que descumpriu a norma imposta pelo tirano porque esta infringia uma norma dos deuses, a que garantia o sepultamento do corpo dos mortos. Ainda, segundo Antígone, ela apenas seguia "as leis divinas, que nunca foram escritas, mas são irrevogáveis; não existem a partir de ontem, ou de hoje; são eternas, sim!, e ninguém sabe desde quando vigoram!".

O mesmo tema volta à tona em outra obra de Sófocles, chamada Ájax. O personagem principal, que dá nome à peça, um grande guerreiro da Grécia Antiga, se suicida ao descobrir que praticou atos contra seu próprio exército em um acesso de insanidade. Menelau e Agamemnom proíbem que seu meio-irmão, Teucro, realize o sepultamento do corpo, como forma de punição pelos seus atos. Mas ao final do texto, o pior inimigo de Ájax, Odisseu, é que aparece para pedir que este tenha o funeral que "todos os homens merecem" no que foi atendido. 
Ainda sobre o Direito Natural, São Tomás de Aquino, já na Idade Média, volta a colocar certos direitos como frutos divinos, e que apenas a partir desses direitos é que o homem deveria criar as normas positivadas, escritas. Dividia as normas jurídicas em três categorias, a das Normas Eternas, as Naturais e as Humanas. Entretanto, sua teoria objetivava claramente subordinar a criação das normas jurídicas aos interesses da Igreja, sendo atacado justamente por isso nos séculos seguintes.

Mantendo o conceito de Direito Natural, entretanto sob outro foco, John Locke pregou que alguns direitos do homem são inerentes à sua natureza, como o direito à liberdade e à propriedade. Assim como é homem, é livre e pode ter propriedades, por exemplo.

Já para Hobbes, o homem em seu estado natural vivia em guerra, em um estado em que ele era seu próprio lobo. Por isso a existência de um Direito Natural que objetive a pacificação dos seres humanos que vivem em sociedade. Este conceito de Hobbes foi atacado por antropólogos, como na afirmação de Richard Leakey, que diz que o homem, como um ser cultural, não é naturalmente nem agressivo e nem pacífico. Talvez em estágios anteriores ao processo cultural o homem fosse guiado por instintos algumas vezes mais agressivos e outras vezes mais pacíficos, mas após a criação do "superorgânico" ver a definição de Kroeber neste texto o homem deixou de ser naturalmente predeterminado para ser culturalmente determinado. Não somos inatamente nada"

Mesmo as noções de Direito Natural criadas posteriormente, como as teorias de Rousseau e de Locke, não são aceitas pela Antropologia, uma vez que partem de princípios apriorísticos. O homem não parece, aos antropólogos, carregar qualquer carga de naturalismo em seu comportamento após certa idade. Até mesmo os instintos são sobrepostos pelo "comportamento cultural"

Para os seguidores das teorias do Direito cultural, a conhecida Escola Clássica do Direito não encontra fundamentos que a sustente. O Direito, para eles, deve ser entendido como fruto do conhecimento, da "cultura" do homem.

IV.b.

O positivismo jurídico, que dispensa maiores apresentações, conseguiu preencher uma série de lacunas deixadas pelo Direito Natural, mas se deparou com alguns pontos que não pôde responder sein fazer algum tipo de concessão. Alguns abaixo:

Como justificar a existência de "sensos comuns" de Direito entre povos distintos, sem aparentemente qualquer ligação? E de onde emana o poder das normas materiais senão de um Direito Natural do homem?

Kelsen, da Escola de Viena, e opositor da Escola Clássica do Direito, esboçou uma explicação com seu conceito de norma fundamental pressuposta. Segundo 
ele, a norma fundamental provém de uma Constituição "produzida através do costume ou da elaboração de um estatuto, eficaz em termos globais"'2 Além disso, a norma fundamental pressuposta deve figurar na premissa maior de um silogismo em que não se pode determinar a pessoa de onde emana o poder da norma, ou seja, a norma fundamental não emana de ninguém ou de nada especificamente. Existe, e isso foi levantado por uma série de críticos, na afirmação kelseniana, uma tautologia, já que esta não se presta a provar a existência da norma fundamental, apenas a utiliza como justificativa para a legalidade em seu positivismo. O uso da expressão "termos globais" também compromete esse entendimento para os adeptos da teorja antropológica do Direito, na medida em que generaliza a norma fundamental a todo o globo, a todos os homens. O conceito de norma fundamental de Kelsen também não explica como alguns direitos tidos como fundamentais a alguns povos não o são para outros. Mesmo que utilizando o termo "costume": Kelsen não admite a existência de diversas normas fundamentais. Esta é única a todos os homens. O referido conceito kelseniano figuraria, portanto, muito mais próximo do Direito Natural do que do Direito Positivo propriamente dito, não fosse seu objetivo a construção de uma ciência pura do Direito. Ele, portanto, não estava interessado em justificar absolutamente todas as situações jurídicas, mas ocupava-se de evitar que a ciência jurídica se valesse de delibações de outras ciências, não sendo, portanto, totalmente autônoma.

Segundo o Direito pressuposto existe uma resposta para a questão acima, que agora buscaremos clarear de forma bem sucinta. Como fruto cultural, o Direito ladeia a língua, a economia e os demais conhecimentos do homem. É parte de um todo social complexo, portanto dependente dos demais produtos do ser humano. Assim, não há que se falar em Direito Natural como algo transcendental, ou em norma fundamental com validade global; fale-se, sim, de direitos culturais, de noções intrínsecas a cada cultura e, conseqüentemente, jamais de um Direito único. As normas humanas, mesmo as fundamentais, só existem quando criadas e desejadas por aquele grupo cultural - ou continente cultural, segundo o professor Miguel Reale - e não há a necessidade de se pensar em normas divinas ou normas fundamentais dando o necessário suporte: basta a vontade daqueles que as criaram, aqueles mesmos a quem elas se destinam.

O Direito antropológico nos serve muito bem para explicar o que os conceitos anteriores, naturalistas ou positivistas, não faziam. Tome-se como exemplo a questão levantada acima sobre a razão que leva alguns povos a terem certos direitos por fundamentais e outros assim não os considerarem. Segundo o Direito pressuposto isso ocorre porque os princípios dos dois ordenamentos são distintos, vez que emanam de culturas distintas. Não existe relação maior entre os direitos do que existe entre as culturas dos povos. Apenas na mesma medida em que aquelas são similares poderão os direitos - direitos no plural mesmo - serem coincidentes, inclusos aqui os seus princípios.

12. H. KELSEN. Teoria Pura do Direito, 6ª ed., Coimbra, Armênio Amado, 1984. 
VI. A contemplação da theoria - a relação entre o Direito pressuposto e a antropologia.

Diz-se pacificadora uma nova tese científica quando esta consegue sanar os conflitos decorrentes do não-entendimento entre doutrinadores de teses nãoconsoantes. Assim foi considerada a Antropologia, pelo menos em certos aspectos, quando conseguiu explicar uma série de indagações que as gerações anteriores a ela não vislumbravam responder.

Um exemplo. Segundo Heródoto, um rei egípcio resolveu elaborar um experimento em busca da "língua natural" dos homens. Para isso, isolou um grupo de crianças e apenas as trouxe de volta ao convívio social após crescidas. Para sua surpresa, a única expressão que emitiam era algo semelhante aos cabrejos; isso se deu porque tiveram como companhia, durante o período de seu desenvolvimento, apenas cabras.

Restou claro, após o desenvolvimento da Antropologia, que o homem não tem uma língua natural por uma série de razões, sanando as dúvidas que suscitavam conflitos entre as teorias anteriores.

Segundo $\mathrm{Kroeber}^{13}$, o homem desenvolveu um ferramental próprio, chamado cultura, que o permite ir além dos limites biológicos, como voar, negociar e organizar-se social e juridicamente; por isso é o homem "superorgânico" É superorgânico porque não depende mais unicamente de seu organismo, ou seja, da natureza, para sobreviver; é capaz de, em vez de aguardar alguns milhares de anos para se adaptar a um ambiente frio, por exemplo, fazer um lar, mesmo que de gelo, e viver dentro dele aquecido sem precisar daquela pelagem extensa ou de uma vasta camada de gordura sob a pele, como o que ocorre com os demais animais polares.

Esse ferramental não se transfere biologicamente mas apenas através dos símbolos e das línguas. Com essa explicação tornou-se possível a definição do objetivo da Antropologia, elaborado por Geertz ${ }^{14}$ : tentar conciliar a unidade biológica humana com sua diversidade cultural.

O conflito que afligia o antigo rei egípcio foi então apaziguado: o homem, apesar de sua natureza comum, sustenta-se sobre culturas diferentes, não existindo uma "cultura natural" dos seres humanos.

No mesmo sentido, o Direito pressuposto pode também ser considerado pacificador. A primeira grande dedução que se pode extrair dessa noção é que não existe superioridade entre os diferentes direitos. Da mesma forma que o unilinearismo hierárquico de Tylor é hoje ultrapassado, assim também o é qualquer busca por um Direito mais desenvolvido em relação aos demais. Cada ordenamento jurídico, ao menos no plano da idéias, é o melhor para aquele grupo social, pois é desenvolvido de acordo com as necessidades específicas do grupo, sejam elas econômicas, sociais, morais, religiosas ou de qualquer outra natureza. Não deve o cientista jurídico despender suas

13. A. KROEBER, $O$ superorgânico ... vide nota 3.

14. C. GEERTZ. A transposição ... vide nota lh 10 pág. lh 6. 
pesquisas em busca dos princípios do Direito - atente para a junção da partícula de com o artigo definido o - sob pena de que nenhum resultado será alcançado.

O máximo que se pode fazer é pesquisar os princípios de determinado Direito, assim como se estuda a composição da música de determinado grupo social de acordo com as escalas, que podem ser diatônicas, pentatônicas ou cromáticas, mas não se estuda qual a escala musical é a correta, já que os sons pertencem à natureza e as notas musicais à cultura humana. Tais escalas vêm sendo adaptadas desde Pitágoras para que respeitem o mais possível a ordem natural dos sons, mas mesmo com a criação das escalas temperadas ou com o desenvolvimento de modernos aparelhos para a medição das frequiências das ondas sonoras, jamais será possível dizer que determinada escala é mais adequada do que as outras justamente porque elas têm como base noções culturais.

Como exemplo dessa impossibilidade de se determinar conceitos culturais como sendo naturais podemos, mantendo o exemplo das escalas musicais, citar uma parte da evolução destas. Seguindo uma tendência cultural de matematização das notas, com a descoberta dos logaritmos tornou-se possível "fechar" as escalas musicais, o que levou à criação das escalas temperadas ou cromáticas. Baseados em tal ferramental surgiram diversos estudos sobre a forma matemático-natural das músicas, como os trabalhos $O$ Cravo Bem Temperado e Tratado da harmonia reduzida a seus princípios naturais, obras datadas de 1722 realizadas pelos "pesquisadores musicais" Bach e Rameau, respectivamente.

A música parecia, portanto, ser uma ciência acabada, que já havia encontrado a sua "equação fundamental" baseada nos "tons naturais matematizados". Entretanto, no início do século XX, Debussy abandona a organização hierarquizante da música clássica e passa a valorizar modos mais antigos e os sistemas orientais de organização dos sons.

Apenas alguns anos após o trabalho de Debussy, volta à cena musical com grande força a busca pelos sons naturais, mas desta vez amparada não pelas descobertas matemáticas, mas sim pelos avanços tecnológicos que proporcionaram as gravações dos sons da natureza. Surgiu, assim, a música eletroacústica dos anos 40 que, ao mesmo tempo, tornava a música muito mais próxima dos sons naturais conforme buscavam os clássicos dos anos 1700 - e fazia uma enorme revolução ao estilo de Debussy - abandonando totalmente a necessidade não-só de se ter escalas musicais como a de se ter um intérprete para as músicas.

O mais significante de todo o exposto é que a cultura humana de cada período fez com que os estudos musicais caminhassem em sentidos diferentes. As descobertas matemáticas dos logaritmos favoreceram a música clássica e a busca pelo natural; as pesquisas sobre outras culturas, principalmente as mais antigas e as orientais, bem como o surgimento de um sentimento de inovação, possibilitaram a Debussy praticamente abandonar o clássico e a natureza e partir em busca de um conceito posto - por ele - de organização sonora; por fím, em nosso exemplo, as invenções tecnológicas oriundas do desenvolvimento trazido pela Segunda Guerra Mundial 
permitiram aos músicos eletroacústicos uma volta aos princípios clássicos ao mesmo tempo que faziam uma nova ruptura. Conclui-se que a música, assim como o Direito, não tem um cerne, um bojo comum a todas as suas definições, mas depende da cultura ao seu redor.

VII. Os direitos culturais.

Um dos autores que nos traz, contemporaneamente, a noção de Direito como um fenômeno cultural é o professor Eros Roberto Grau ${ }^{15}$ que o divide em posto e pressuposto. Segundo o professor, o Direito deve ser dividido entre aquele que é pressuposto na sociedade, que faz parte da cultura daquele povo; e o Direito posto, colocado pelas leis como fruto do primeiro.

Originada no final do século XVII e desenvolvida durante o século XIX por Savigny em sua Escola Histórica do Direito, a Teoria Culturalista avançou bastante com os estudos da Escola de Baden, liderada por Emil Lask, Gustav Radbruch e com a vertente originada da Teoria da Tridimensionalidade do Direito, de Miguel Reale. Entretanto, o prisma utilizado pelo Direito antropológico é ainda um pouco diferente.

As correntes culturalistas atentaram para um importante aspecto da formação do Direito: ele é cultural. Para os culturalistas ${ }^{16}$ o Direito objeto da Ciência do Direito deve estar fixado no tempo e no espaço, ou seja, culturalmente determinado. Mas, segundo tal Escola, ainda existe algo em comum entre todos os direitos, sua manifestação é que se dá de forma diferente nas culturas. Para o Direito pressuposto esse ponto comum entre os direitos, de forma isolada, não existe, apenas existem pontos comuns entre as culturas e os direitos, e estes, como parte da cultura, acabam por ter alguns aspectos similares. Uma maior distinção entre o exposto por culturalistas, como Radbruch, e o que defende o Direito poderá ser percebida abaixo, quando o Direito Internacional for o alvo de nossos estudos.

VIII. Dialética descendente - o Direito pressuposto na prática.

No campo das pacificações trazidas pelo Direito pressuposto - quando utilizamos o termo no singular estamos fazendo referência à teoria, e não aos direitos pressupostos - uma das primeiras que se pode alicerçar é a questão da legitimidade. $O$ fato de se considerar o Direito como linguagem cultural do homem social, ou seja, como conjunto de símbolos para a comunicação entre comunicante e comunicado, justifica a força coercitiva do Direito posto. O Direito posto só é legítimo e tem força quando é positivação do Direito pressuposto; em última instância, quando reflexo do interesse social. A força do Direito não vem, portanto, de deuses ou de normas

15. E. R. GRAU, Direito Posto e Direito Pressuposto, São Paulo, Malheiros, 1996.

16. M. REALE, Teoria Tridimensional do Direito, 5² ed., São Paulo, Saraiva, 1994. 
fundamentais, mas sim da vontade dos povos, ou seja, do Wolksgeist proposto por Savigny.

É interessante notar aqui que semelhante citação já fora feita por São Tomás de Aquino quando disse que qualquer lei estabelecida pelos homens é autêntica na mediaa eń que deriva da lei da natureza, se discordar desta já não será lei, mas corrupção da lei. Apenas devemos notar que a derivação da natureza, para que sua citação fique de acordo com o Direito antropológico, deve fazer referência à derivação da cultura do povo e não da natureza no sentido transcendental que o termo assumia em sua obra.

Uma situação prática em que o Direito pressuposto pode servir de pacificador é a questão dos conflitos entre as fontes de Direito, principalmente entre tratados e convenções de Direito Internacional Público frente ao Direito Constitucional, óbvio, interno.

Muito se discute acerca do tema, havendo doutrinas que bradam pela supremacia dac Constituição, não sendo esta revogável por tratado posterior ou anterior ver Carlọs Maximiliano, Hermenêutica e Aplicações do Direito -, outros que dizem a questão depender da anterioridade de um ou de outro - ver Haroldo Valladão, D.I.P. e os que pregam a supremacia das convenções internacionais - ver Hildebrando Accioly, Manual de Direito Internacional Público.

Sobre a questão acima, segundo o Direito pressuposto, considerando o Direito como um produto cultural em que o homem cria e é criado através dele, percebemos que as definições doutrinárias muito seguras e rígidas são as mais frágeis frente à "natureza cultural" inconstante e maleável do homem. Não se pode, assim, afirmar que os tratados se sobrepõem à Constituição ou vice-versa sem saber qual é o desejo do complexo social. Dependendo do Direito criado por aquela comunidade poderão os tratados internacionais serem aceitos com um peso maior ou menor que o da Constituição. E isso varia no espaço, no tempo e, a partir do Direito pressuposto, em mais uma dimensão, no interior cultural-social de cada grupo. Não bastam análises exaustivas do corpo legal positivo, isso não passará de uma análise indireta do Direito verdadeiro, que está junto à sociedade. Aqui fazemos, mais uma vez, referência aos estudos de Miguel Reale. Qualquer teoria que busque "comprovar cientificamente" que determinado Direito será o correto, ou o realmente válido, está fadada a não durar mais do que por um curto período de tempo, em um pequeno espaço e, ainda, de forma restrita ao interior cultural-social dos grandes grupos que formam o Povo de um Estado e que concordam com a teoria e a aceitam.

Nem mesmo a Constituição pode estar acima do Direito antropológico: o que ela pode é materializar determinados princípios ou interesses de determinado momento, mas deve estar sempre apta a se transformar de acordo com os interesses do grupo a partir do qual é criada e que ajuda a criar.

O próprio Direito Internacional pode ser discutido sob a visão do Direito antropológico. Existe alguma cultura que seja totalmente comum a todos os homens? Se existir tal parcela, ela com certeza será ínfima se comparada à diversidade cultural 
humana. Da mesma forma o Direito Internacional só pode existir nas mesmas proporções em que todas as culturas tenham aspectos comuns.

De fato, o Direito Internacional ainda mantém estreitos laços para com as Leis de Talião ou o Código de Hammurabi. Ainda vigora como um dos termos mais utilizados do Direito Internacional o "direito de retaliação". Não existe uma lei que obrigue a todos os países porque não existe uma cultura comum entre todos eles. Não se pode imaginar uma lei cogente sem que uma vontade comum dos homens a crie, segundo o Direito antropológico. Por isso, no âmbito do Direito Internacional, a Espada se sobrepõe à Balança; a imperatividade das normas e das decisões só existe como fruto da força dos países e não como fruto de uma cultura amplamente aceita. Ainda vale, no Direito Internacional, boa parte dos ensinamentos de Espinoza, que via na força a justificação do Direito e do Estado, só sendo inviolável o pensamento em razão de sua natural inviolabilidade ${ }^{17}$

Aqui pode ser feita nota a respeito da diferença entre a Teoria do Direito cultural de Radbruch e a apreciada pelo Direito antropológico. Segundo aquele, assim se apresenta o Direito Internacional na questão referente à Soberania:

"Vendo as coisas através do dogma da soberania, pode dizer-se que as dificuldades e contradições que aí surgem são as mesmas que surgem nas relações entre o Estado e a Igreja, quer na teoria legal, quer na dos privilégios, em matéria de concordatas. Para cada Estado em face de todos os outros, tanto o reconhecimento por ele prestado a estes, como a promessa de cumprir qualquer contrato com eles, nunca poderão deixar de se the apresentar com o caráter duma concessão graciosa, outorgada por um ato jurídico unilateral. Assim, o quadro que o dogma da soberania nos pinta da vida jurídica dos Estados nas suas mútuas relações de coexistência, está longe de ser duma comunidade jurídica entre sujeitos de direitos iguais, obrigados a um reciproco reconhecimento. Assemelha-se antes ao duma arena povoada de feras. Cada uma delas pretende para si todo o espaço em volta. Mas como nenhuma pode destruir ou expulsar as outras, daí resulta que todas se vêm obrigadas a tolerarem-se mutuamente, rodando continuamente em volta umas das outras, arreganhando os dentes e rugindo" 18

Note-se - e essa é uma das diferenças entre o Direito Antropológico e o Direito Cultural - que, nos dias atuais, com o aumento da integração entre os povos e o conseqüente incremento da parcela comum da cultura, temos um acréscimo também no Direito Internacional antropológico e, portanto, legítimo. Mas ainda existe muita divergência cultural entre os povos para que se fale em um Direito Internacional amplo, com as pessoas físicas figurando como sujeitos de direito. Isso só é possível em locais onde a cultura nuclear de cada povo já se apresenta consolidada e que, portanto, a entrada de outras culturas ocorre de forma não-prejudicial, como no caso da Europa.

17. G. DEL VECCHIO, Lições de Filosofia do Direito, traduçāo de Antônio José Brandão, $5^{\circ}$ ed. traduzida, $10^{\circ}$ ed. ilaliana, Coimbra, Armênio Amado, 1979.

18. G. RADBRUCH, Filosofia do Direito, Coimbra, Armênio Amado, 1997. 
Os países europeus já têm, cada um, sua formação cultural bem determinada, o que lhes propicia a chance de um caminhar rumo a uma cultura geral de seu povo e, conseqüentemente, à construção de um Direito comum, como está previsto para a União Européia para o ano de 2009.

Mas o Direito Internacional, de forma geral, é ainda pouco fundamentado em normas culturais. As anomalias dessa forma de Direito - que, para o Direito antropológico, não chega a ser um Direito mesmo - são inúmeras, como por exemplo, quando um Estado com força maior que os demais decide, unilateralmente, não se submeter às regras que os outros estão tentando impor e nada se pode fazer. Veja, para ilustrar, o caso do ataque gerido pela OTAN aos Bálcãs sem o consentimento do Conselho de Segurança da ONU.

Se não existe uma cultura que imponha as normas, estas não existem senão no plano das teorias que a aceitam. As normas que não decorrem do Direito ou, em última instância, da cultura, são aquelas que não produzem efeitos, são mitigadas no plano da eficácia.

Os próprios Direitos Humanos estão sujeitos aos direitos antropológicos e, por isso, dificilmente algum dia serão totalmente aceitos e respeitados. Aplica-se o mesmo raciocínio que serviu ao Direito Internacional. Apesar dos enormes esforços para que todos os povos respeitem os Direitos Humanos, é pouco provável que se convença quem foi criado fora da cultura ocidental pós-Revolução Francesa de sua importância e de seu valor, para nós, universal. Apenas com um grande movimento de imposição cultural isso seria possível. Mas nesse caso estaríamos trocando uma violência por outra: o processo de aculturação dos povos.

Mesmo que nos pareça uma violência menor retirar certos aspectos culturais de determinados grupos para que estes aceitem, por exemplo, os Direitos Humanos, para eles isso pode representar muito mais do que podemos perceber em uma primeira análise. Conforme já foi dito diversas vezes, o homem é fruto da cultura e esta fruto dele: retirar alguns aspectos da cultura de um povo significa retirar parte do próprio homem criado nela. É mesmo uma mutilação do Volks.

Para ilustrar esse tipo de violência, vale citar o escritor Ariano Suassuna, que coloca-se totalmente contrário ao processo de globalização, já que este tem sido feito sempre de forma unilateral. Não existe globalização propriamente dita, não existe troca de idéias, experiências, enfim, de cultura, mas apenas a entrada, de forma brusca, de costumes dos países economicamente mais fortes sobre os menos favorecidos. Suassuna, parafraseando idéia de Machado de Assis sobre a divisão do Brasil, chegou a dizer: a globalização imposta pelo Brasil Oficial - aquele das grandes cidades -, está destruindo o Brasil Verdadeiro - o Brasil não-globalizado. O mesmo vale para a imposição cultural entre países.

Assim, não sendo os direitos superiores a nenhuma cultura, haja vista que sua relação é de inserção nas culturas, enquanto todos os povos não aceitarem, em um processo que deve ser iniciado no seu interior cultural, os Direitos Humanos, estes jamais terão validade universal. Sua imposição de qualquer outra forma, além de 
representar uma violência, jamais trará os resultados esperados. É preciso muita cautela quando se fala na aplicação global de qualquer Direito, seja ele humano ou nacional, para que não se cometa com a cultura jurídica o mesmo que se vem fazendo para com os demais ramos da cultura.

IX. O problema da Teoria do Direito pressuposto.

Já vimos uma série de razões para que as diversas escolas do Direito, como a do Direito Natural ou a do Direito Positivo, fossem consideradas, hoje, isoladamente, inadequadas. E não há motivos para que o mesmo não aconteça com o Direito pressuposto ou antropológico. Por isso já nos adiantamos e mostramos aqui um dos maiores problemas para a verificação de tal Teoria.

A Teoria do Direito pressuposto - ou antropológico -, por ser ela ao mesmo tempo cria e criadora da cultura humana, por estar no mesmo nível que os. demais frutos culturais, enfrenta um paradoxo, similar àquele das duas cobras que estão se devorando uma a cauda da outra: supondo ser uma verdade absoluta que o Direito é fruto cultural, se determinada cultura estabelecer que o Direito não pertence à cultura - pode dizer, por exemplo, que ele é natural -, ele então não será pertencente à cultura, mesmo que para que isso se torne verdade, para que o dizer jurídico tenha força, o Direito precise pertencer à ela.

Como em toda ciência, principalmente nas humanas, dificilmente uma teoria será eterna. Se o paradoxo acima for problema bastante para a sustentação do Direito pressuposto, então este está já está também fadado a ser, em breve, superado por mais alguma nova teoria.

Além disso, o Direito pressuposto cuida apenas do aspecto fenomenológico do Direito - que, para essa teoria é o bastante. Entretanto, aos olhos dos seguidores de outras escolas, o Direito cultural é falho ao não atentar para os aspectos lógicos e deontológicos da Filosofia do Direito, ou seja, das relações do Direito com a Moral e outras áreas afins e das relações entre seus sujeitos, bem como não se foca sobre a atuação normativa, deôntica.

Assim, face às inúmeras críticas que se pode fazer, concluímos apenas que certo estava James Joyce em seu Finnegans Wake:

\section{Introdução.}

Segundo Miguel Reale, é papel da Filosofia do Direito responder a essas três questões básicas $O$

São Paulo, outubro de 2002. 